\title{
MEMÓRIA, IMAGINÁRIO E DIREITO AO ESQUECIMENTO: AS DISPUTAS DE SENTIDOS PARA O SUJEITO EX- CONDENADO EM COMENTÁRIOS DIGITAIS
}

\author{
MEMORIA, IMAGINARIO Y DERECHO AL OLVIDO: LAS DISPUTAS DE \\ SENTIDOS POR EL SUJETO EX-PRESO EN COMENTARIOS DIGITALES
}

MEMORY, IMAGINARY AND THE RIGHT TO BE FORGOTTEN: THE DISPUTES OF MEANINGS FOR THE EX-CONVICT SUBJECT IN DIGITAL MEDIA COMMENTS

DOI: $10.22481 /$ rbba.v10i02.9558

Gerenice Ribeiro de Oliveira Cortes Universidade Estadual do Sudoeste da Bahia, Vitória da Conquista, Bahia, Brasil Lattes: http://lattes.cnpq.br/5407186161806188 ORCID: https://orcid.org/0000-0001-6597-6192 Endereço eletrônico: cortesgr@gmail.com

Ihasmyn Camilla Ferreira Silva Universidade Estadual do Sudoeste da Bahia, Vitória da Conquista, Bahia, Brasil

Lattes: http://lattes.cnpq.br/5260164694868751 Endereço eletrônico: ihasmyn_camilla@hotmail.com

\section{RESUMO}

$\mathrm{O}$ artigo tem por objetivo analisar a construção discursiva do sujeito ex-condenado nas mídias digitais, como também as discursividades sobre as tentativas de reinserção social desse sujeito e sua (re)construção identitária. O estudo respalda-se teoricamente nos pressupostos da Análise de Discurso (AD) de filiação pecheuxtiana, além das constatações doutrinárias sobre o Direito ao Esquecimento e sua prática jurisprudencial na seara criminal. O corpus foi construído de um recorte de oito comentários digitais sobre 
uma matéria jornalística que aborda a temática da ressocialização do ex-condenado. As análises mostram uma forte tensão instaurada entre a memória sobre o sujeito excondenado e a (re)construção de uma nova memória discursiva, qual seja a de um cidadão. Nessa trama, as projeções imaginárias de não-pessoa determinam sentidos para a exclusão social do ex-detento e instauram, no discurso, uma posição-sujeito punitivista. Os discursos em funcionamento nas mídias digitais e redes sociais, dadas as suas condições de produção e de circulação, produzem efeitos de apagamento de sentidos de cidadania para o exdetento, e assim, dificulta a sua ressocialização.

Palavras-chave: Direito ao Esquecimento; memória discursiva e imaginário; ressocialização do Ex-condenado; discurso midiático digital.

\section{RESUMEN}

El artículo tiene como objetivo analizar la construcción discursiva del sujeto exconvicto en los medios digitales, así como los discursos sobre los intentos de reinserción social de este sujeto y su (re) construcción de identidad. El estudio se sustenta teóricamente en los supuestos del Análisis del Discurso (AD) de la filiación pecheuxtiana, además de los hallazgos doctrinales sobre el Derecho al Olvido y su práctica jurisprudencial en el ámbito penal. El corpus se construyó a partir de un recorte de ocho comentarios digitales sobre un reportaje periodístico que aborda el tema de la resocialización del exrecluso. Los análisis muestran una fuerte tensión establecida entre la memoria del sujeto exconvicto y la (re) construcción de una nueva memoria discursiva, la de un ciudadano. En esta trama, las proyecciones imaginarias de la no persona determinan significados para la exclusión social del ex-preso y establecen, en el discurso, una posición de sujeto punitiva. Los discursos que operan en los medios digitales y las redes sociales, dadas sus condiciones de producción y circulación, producen efectos de borrar el sentido de ciudadanía al ex-preso $\mathrm{y}$, por tanto, dificulta su resocialización.

Palabras clave: Derecho al olvido; memoria discursiva e imaginario; resocialización del ex preso; discurso de los medios digitales.

\section{ABSTRACT}


The article aims to analyze the discursive construction of the ex-convict subject in digital media, as well as the discourses on the attempts of social reinsertion of this subject and his identity (re)construction. The study is theoretically supported by the assumptions of Discourse Analysis (AD) of pecheuxtian affiliation, in addition to the doctrinal findings on the Right to be Forgotten and its jurisprudential practice in the criminal area. The corpus was built out of na excerpt of eight digital comments on a journalistic story that addresses the theme of the resocialization of the ex-convict. The analysis show a strong tension established between the memory of the exconvict subject and the (re)construction of a new discursive memory, namely that of a citizen. In this plot, the imaginary projections of the non-person determine meanings for the ex-convict's social exclusion, and establish, in the discourse, a punitive subjectposition. The current discourses in digital media and social networks, given their conditions of production and circulation, produce effects of erasing the sense of citizenship for the ex-convict, and thus makes their re-socialization difficult.

Keywords: Digital media discourse. Discursive and imaginary memory. Resocialization of the exconvict. Right to be Forgotten.

\section{INTRODUÇÃO}

No atual período de economia globalizada, as tecnologias digitais estão cada vez mais velozes, com grande capacidade de expansão e celeridade na difusão de informações diversificadas, que também se caracterizam pela volatilidade. As mídias digitais online proporcionam o encurtamento virtual das distâncias geográficas e se transformaram em um espaço para a produção, divulgação, compartilhamento e circulação na/em rede mundial de computadores (Internet), que também é uma rede de discursos e memórias em movimento incessante, na tensão entre a retomada de já ditos, não ditos, equívocos e deslizamentos de sentidos.

Nessa conjuntura, a ideologia midiática sensacionalista e espetaculosa, dominante em alguns telejornais, que abordam fatos criminais com efeitos dramáticos e de grande comoção (LEITE, 2017), também interpela os internautas para esse posicionamento, sobretudo nas práticas discursivas dos comentários das postagens jornalísticas. Os comentários digitais

Revista RBBA $\mid$ Revista Binacional Brasil Argentina Vol. 10, num. 2, dez/2021, p. 390-405 
alavancam ainda mais o processo da repetibilidade de sentidos, e funcionam com efeitos de motorização digital.

Em se tratando da discursivização de fatos criminais, essa repetibilidade pode produzir efeitos mórbidos para a sociedade, já que "A frequente exposição do fato criminal, por intermédio da mídia, tem constituído memórias flash, cujos sentimentos envolvidos vêm provocando repercussões fóbicas na consciência coletiva [...]” (LEITE, 2017, p. 3). Desse modo, as narrativas midiáticas espetacularizadas e massivamente repetidas acerca de práticas criminosas trabalham para fixar uma projeção imaginária do sujeito criminoso e de seu lugar na sociedade, mesmo após o cumprimento da respectiva pena.

Neste estudo, nosso intuito é analisar as disputas de memórias em funcionamento na (re)construção da identidade do sujeito ex-condenado, a fim de compreender os efeitos de sentidos que se instauram sob os embates discursivos travados entre o emergente Direito ao Esquecimento - que busca proteger o uso da imagem do ex-apenado - e o discurso do clamor midiático social, que funciona em defesa da perpetuidade da pena moral.

Nos respaldamos teoricamente nos aportes da análise de discurso de filiação pecheuxtiana. Em especial, mobilizamos as noções de memória discursiva, formações imaginárias, posição-sujeito, política do esquecimento e política do resgate da memória (INDURSKY, 2015); ademais, temos as contribuições da ciência jurídica, no que tange ao conceito Direito ao esquecimento.

O corpus foi constituído por um recorte de oito comentários digitais, realizados por internautas a partir da leitura da matéria jornalística intitulada "Ex-detentos lutam contra o preconceito por oportunidade no mercado trabalho", publicada pelo portal de notícias G1, em 2019. Os comentários foram organizados em três sequências discursivas (SD’s), mediante a captura de tela de imagens.

Antes de adentrar em nossos gestos de análise, faremos uma breve discussão sobre os conceitos teóricos mobilizados para o estudo.

\section{Discurso, sujeito, memória e formações imaginárias}

No quadro teórico da análise de discurso de base pecheuxtiana, a produção do sentido se dá juntamente à constituição do sujeito e tem a língua como sua base material (PÊCHEUX, 2009). Segundo Maldidier (2003), a teoria do discurso, construída por Pêcheux é um verdadeiro

Revista RBBA $\mid$ Revista Binacional Brasil Argentina Vol. 10, num. 2, dez/2021, p. 390-405 
"nó”, intrincado por questões sobre a língua, a história, o sujeito. A autora resume o pensamento do autor, da seguinte forma: "O sujeito não é a fonte do sentido; o sentido se forma na história através do trabalho da memória, a incessante retomada do já-dito; o sentido pode ser cercado, ele escapa sempre" (MALDIDIER, 2003, p. 15).

Nessa perspectiva, o sentido não existe na relação transparente da literalidade do significante, mas sofre determinações das ideologias que estão em jogo no processo sóciohistórico; assim, o autor afirma que: "as palavras, expressões e proposições mudam de sentido segundo as posições sustentadas por aqueles que as empregam [...] elas adquirem seu sentido em referência a essas posições (PÊCHEUX, 2009, p. 146, grifos do autor). Nessa direção, o autor argumenta que a materialidade linguística recebe seu sentido da formação discursiva (FD) em que é produzida, pois é a FD que determina o que pode e deve ser dito, em uma dada conjuntura. E ainda, as FDs - que representam na linguagem as formações ideológicas interpelam os indivíduos em sujeitos falantes de seu discurso ((PÊCHEUX, 2009).

É nas FDs que se forma o interdiscurso, denominado por Pêcheux (2009) como o todo complexo com dominante, ou seja, é um conjunto de FDs em que uma é a dominante. Para o autor o interdiscurso compreende o que fala sempre antes, em outro lugar e independentemente. A forma-sujeito é o que regula o que "pode/deve" entrar na FD. Conforme esclarece Maldidier (2003, p. 51): "o interdiscurso designa o espaço discursivo e ideológico, no qual se desdobram as formações discursivas em função das relações de dominação, subordinação, contradição".

A partir de recortes do interdiscurso, temos a memória discursiva, que se constitui mais especificamente dos saberes de uma dada FD; segundo Indursky (2011), enquanto a memória discursiva é regionalizada, esburacada e lacunar, circunscrita aos saberes de uma FD, [...] "o interdiscurso abarca a memória discursiva referente ao complexo de todas as FD. Ou seja, a memória que o interdiscurso compreende é uma memória ampla, totalizante e, por conseguinte, saturada" (INDURSKY, 2011, p. 87-88). Pensamos também o conceito de memória, nos termos de Pêcheux (2010a), como um dinâmico e tenso jogo de forças, de réplicas, tréplicas e contradiscursos; como acontecimento a ler que estabelece a condição do legível em relação ao próprio legível.

Nessa trama discursiva, o sujeito é também afetado pelo interdiscurso, não é dono do seu dizer, pois se constitui como uma posição discursiva entre outras, nas relações com as formações discursivas, que são constitutivamente marcadas pela instabilidade e heterogeneidade. Courtine e Marandin (2016, p. 39) consideram uma FD como: "heterogênea

Revista RBBA $\mid$ Revista Binacional Brasil Argentina Vol. 10, num. 2, dez/2021, p. 390-405 
em relação a si mesma: o fechamento de uma FD é fundamentalmente instável". Nessa trama, o sujeito é dividido e a língua se constitui da falha e do equívoco, o que possibilita a movimentação dos sentidos.

Assim, a FD constitutivamente heterogênea, apresenta uma posição-sujeito dominante ao lado de outros desdobramentos da forma-sujeito que se fragmenta nos processos de subjetivização (INDURSKY, 2008). Portanto, o sujeito pode fragmentar-se em posições diferenciadas, em uma mesma FD. Courtine (2009, p. 88) define uma posição de sujeito como [...] "uma relação determinada que se estabelece em uma formulação entre um sujeito enunciador e o sujeito do saber de uma dada FD. Essa relação é uma relação de identificação cujas modalidades variam, produzindo diferentes efeitos-sujeito no discurso."

Pêcheux (2010b) defende que todo processo discursivo supõe a existência de formações imaginárias, que projetam o lugar que os sujeitos do discurso se atribuem a si mesmo; um jogo de projeção de imagens dos sujeitos e de seus lugares, que funcionam intrincadamente às condições de produção do discurso, uma vez que os lugares dos sujeitos se encontram representados (presentes, mas transformados) no processo discursivo, como em um jogo de imagens.

Morales (2008, p. 43) declara que as "formações imaginárias estão ligadas às formações ideológicas, as quais constituem um complexo conjunto de atitudes e representações que não são individuais, nem universais, mas se relacionam com as posições de classe." Nesse processo discursivo funciona, portanto, uma antecipação das representações imaginárias dos sujeitos e de seus lugares, sendo que tais imaginários não são fixos, mas se movimentam e funcionam em um complexo e dinâmico jogo de relações, marcado por tensões e embates.

A seguir faremos uma breve explanação acerca do Direito ao esquecimento.

\section{Direito ao esquecimento e punitivismo midiático}

Oriundo dos direitos fundamentais da personalidade que versam sobre a proteção à honra, imagem, intimidade e privacidade, art. $5^{\circ}, \mathrm{X}, \mathrm{CR} / 88$, tendo sede no supraprincípio da Dignidade da Pessoa Humana, no art. $1^{\circ}$, III, CR/88, o Direito ao Esquecimento ${ }^{\mathrm{i}}$ - ou o direito de "estar só", de ser deixado em paz - é definido como uma prerrogativa que todo sujeito de direito dispõe para controlar a circulação digital e midiática de fatos pretéritos, ainda que verídicos, atinentes à sua vida, com a finalidade de evitar diversos prejuízos, dos quais

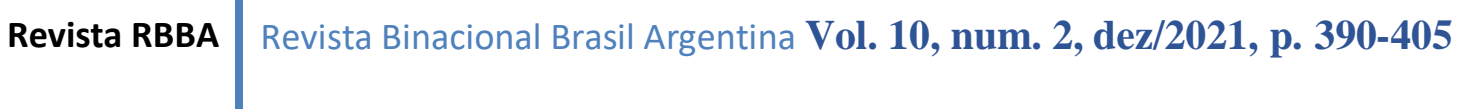


destacam-se: a desnecessária exposição ao público de tal informação e o reavivar sofrimentos dos envolvidos no que diz respeito a vida pessoal (MARTINEZ, 2014).

No Brasil, o Direito ao esquecimento ${ }^{\mathrm{ii}}$, ou de ser deixado em paz, emergiu no âmbito das condenações criminais. De acordo com o Conselho Nacional de Justiça, CNJ, o Direito ao Esquecimento é relevante para a ressocialização de ex-detentos, posto que o seu exercício vai de encontro à perpetuidade da punição social. Pelo Princípio da isonomia, art. 5º, caput, CR/88, o egresso do sistema penitenciário é considerado como qualquer outro cidadão que não cometeu crime. Consequentemente, ele desfruta do direito à intimidade e à privacidade. Destarte, o sigilo de suas informações penais é essencial para a sua reinserção social, conforme expresso em lei, mais precisamente, no que diz respeito ao instituto da reabilitação criminal.

O exercício do Direito ao Esquecimento não consiste no apagamento de fatos passados, mas, em decorrência da superação do crime em face do cumprimento da pena, reconhece-se a possibilidade de comprimir a exploração digital e midiática desnecessária de tais eventos verídicos pretéritos. Ademais, o instituto da reabilitação criminal é uma expressão deste direito emergente. Portanto, sob a égide de resguardar a ressocialização e os direitos da personalidade de ex-detentos, o Direito ao Esquecimento é um marco limitador da liberdade de imprensa. Contudo, ainda não há lei específica positivada que discipline o seu exercício.

Destarte, para o reconhecimento do mencionado direito no caso concreto, a prática jurisprudencial busca analisar: o teor histórico do crime; a atualidade de interesse público na informação e o objetivo de sua publicação, além dos possíveis transtornos que a sua divulgação acarrete para os indivíduos diretamente envolvidos.

Com base nos pressupostos apresentados, passemos ao nosso percurso analítico.

\section{Gestos de Análise}

A matéria "Ex-detentos lutam contra o preconceito por oportunidade no mercado trabalho", publicada pelo portal G1, no dia 26/09/2019 iii abordou histórias de vida de excondenados, preconceito e ressocialização dos egressos do sistema prisional. Todavia, como já mencionado, o nosso olhar nesta análise se volta apenas para os comentários digitais da publicação mencionada, que gerou um acalorado debate entre os internautas.

Ao discorrer sobre o leitor internauta, Cortes (2015, p. 180) declara que: “o leitor é também um sujeito descentrado, já inscrito em um lugar social, a partir do qual pode ocupar

Revista RBBA $\mid$ Revista Binacional Brasil Argentina Vol. 10, num. 2, dez/2021, p. 390-405 
distintas posições-sujeito para interpretar e produzir sentidos." Essa leitura também é realizada sob as condições de produção e circulação das tecnologias digitais, que produzem efeitos e determinações na construção dos sentidos. O leitor se constitui em sua relação com a exterioridade, com o interdiscurso, e assim interpreta, interpelado ideologicamente para se fazer sujeito. Nesta perspectiva: "a leitura é também um ritual aberto a falhas e brechas, que supõe, não um sentido único, mas permite deslizamentos e diversos efeitos de sentidos" (CORTES, 2015, p. 180).

Para o presente estudo, os comentários foram organizados em três sequências discursivas (SD's), das quais apresentamos a primeira (SD1), composta por três comentários digitais.

Figura $1^{\text {iv }}-$ SD1

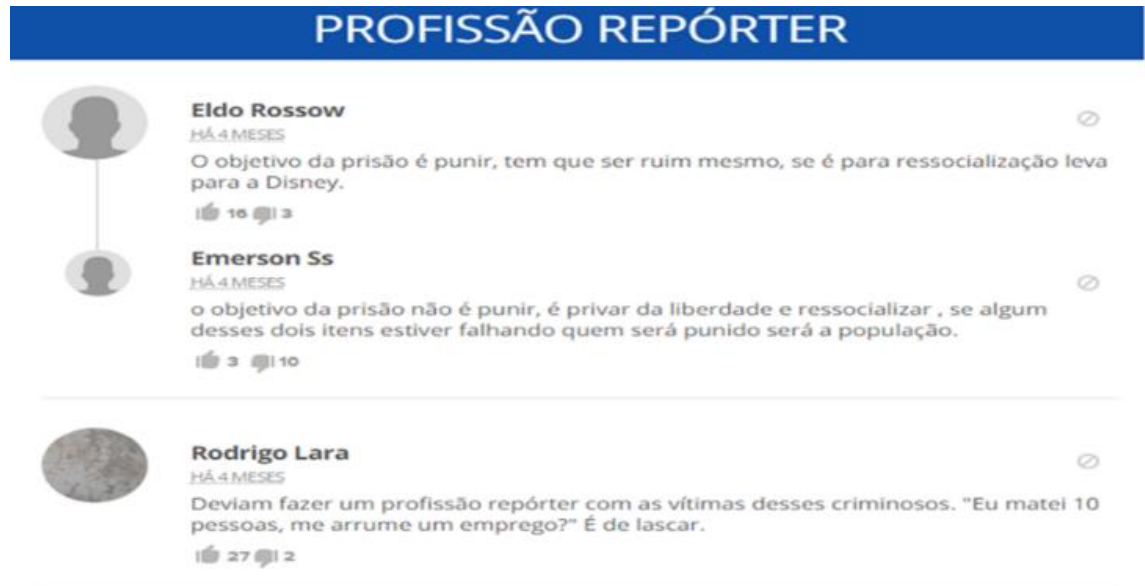

O leitor da matéria e autor do primeiro comentário (E.R.) da SD1, identifica-se com a posição-sujeito punitivista, uma FD dominante no discurso midiático sensacionalista, que determina sentidos de impedimento à ressocialização do ex-detento. Portanto, temos uma relação de antagonismo com a FD jurídica do Direito ao esquecimento. A posição-sujeito punitivista funciona com efeitos de vingança, pelo viés da ironia e, ao mesmo tempo produz o apagamento do sentido da pena, cujas finalidades consistem de: “[...] repressão, prevenção e ressocialização. Enfatizando o caráter ressocializador da pena, ou seja, a volta ao convívio social depois de cumprida a pena imposta pelo Estado, em virtude do delito penal cometido (SANTANA e CRUZ, 2015, p. 297).

No terceiro comentário da SD1 (R.L.), constatamos o movimento parafrástico de sentidos, já que o ex-presidiário continua a ser denominado de "criminoso". No entanto, o ex-

\begin{tabular}{l|l} 
Revista RBBA & Revista Binacional Brasil Argentina Vol. 10, num. 2, dez/2021, p. 390-405
\end{tabular} 
presidiário "deve sim ter o direito a não ser mais assolado pela opinião pública e ainda mais pela imprensa chamada de sensacionalista" (LEMES, 2017, online).

A intensa repetibilidade midiática dos crimes, cujas penas já foram cumpridas, pode produzir efeitos de condenação eterna, como aponta Lemes (2017, online): "Atos pretéritos praticados e já julgados, condenados e cumpridos por ex-presidiários não devem ficar a vida inteira batendo a porta de ser relembrado como uma punitibilidade ad aeternum. O sentido da punitibilidade ad aeternum é um já dito do interdiscurso que se atualiza no discurso enunciado por alguns comentaristas.

O posicionamento da condenação eterna ou punitivista, é efeito do imaginário de "sempre criminoso" para o sujeito ex-detento, visto que, é pelo imaginário que se passa das situações empíricas para as posições discursivas: “[...] São essas projeções que permitem passar das situações empíricas - os lugares dos sujeitos - para as posições do sujeito no discurso. Essa é a distinção entre lugar e posição (ORLANDI, 2012, p. 40).

Sobre a repetibilidade midiática, Indursky afirma que a mídia "produz um processo discursivo que é da ordem da repetibilidade. No seu interior só há espaço para os saberes referentes à Formação discursiva dominante" (INDURSKY, 2015, p.14). Segundo a autora, a repetição midiática se dá à exaustão, até produzir um efeito de verdade. Entendemos que esse efeito de verdade é potencializado pelas condições de produção e de circulação bem peculiares dos discursos em funcionamento nos espaços midiáticos digitais.

Todavia, no embate de forças discursivas, instaura-se o deslizamento de sentidos, como observamos no segundo comentário do leitor E.S. (SD1), onde temos o funcionamento do contradiscurso à punitibilidade eterna, conforme verificamos no trecho seguinte: “O objetivo da pena não é punir, é privar da liberdade e ressocializar" (SD1 - comentário 2). Aqui, temos o equívoco e a falha, pois o enunciador que comenta a matéria ocupa a posição-sujeito contrária ao punitivismo e defende a ressocialização do ex-detento.

Vejamos a SD2, com outros comentários da matéria supramencionada.

Revista RBBA Revista Binacional Brasil Argentina Vol. 10, num. 2, dez/2021, p. 390-405 
Figura $2^{\mathrm{v}}-\mathrm{SD2}$

\section{PROFISSÃO REPÓRTER}

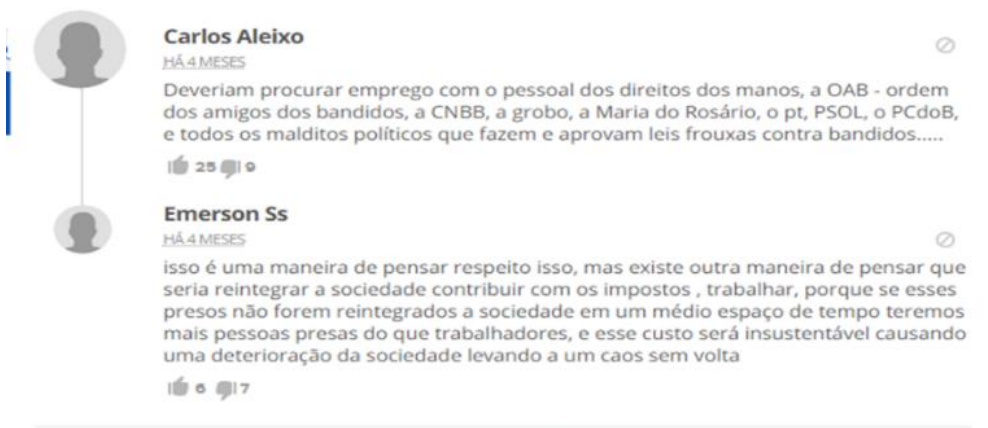

Os embates seguem na seção de comentários da mencionada matéria jornalística. $\mathrm{Na}$ SD2, instaura-se a repetição parafrástica, a exemplo do primeiro comentário do internauta C.A., que ocupa a posição-sujeito punitivista, contrária à ressocialização do ex-detento. Esse discurso produz efeitos de escárnio aos Direitos Humanos, pela substituição metafórica do significante "Direitos humanos" para "direitos dos manos", uma formulação que atualiza sentidos do já-dito para o termo "manos", em referência àqueles que cometeram algum fato criminoso.

Pêcheux argumenta que "O sentido existe exclusivamente nas relações de metáfora (realizadas em efeitos de substituição, paráfrases e formações de sinônimos) [...]” (PÊCHEUX, 2009, p. 240). É, pois, pela metáfora discursiva que se instaura o jogo dos sentidos nos comentários digitais, como também vemos na substituição metafórica da sigla OAB - Ordem dos Advogados do Brasil, para a formulação "ordem dos amigos dos bandidos". Aqui, a ideologia punitivista nega o direito à defesa ao dito "delinquente" e faz apelo ao recrudescimento penal ("leis frouxas"). Além disso, o discurso punitivista inscrito no comentário discursiviza algumas instituições sociais e personalidades políticas, com efeitos de escárnio e sarcasmo, tendo em vista que estas defendem a ressocialização do ex-detento.

E os embates de sentidos seguem nos comentários da SD2, com o segundo internauta, comentarista (E.S.). Nesse discurso, observamos que, embora não haja a defesa do punitivismo, os sentidos de ressocialização não visam à (re)construção da dignidade da pessoa. Ou seja, aqui temos um movimento de contra-identificação com a posição-sujeito punitivista, mas o sujeito é afetado pela ideologia neoliberalista, visto que a motivação para a defesa da ressocialização do ex-detento, tem por base apenas os interesses na mão-de-obra e a contenção de custos ao Estado, tendo em vista os interesses produtivos do discurso capitalista. Tais sentidos podem ser

Revista RBBA $\mid$ Revista Binacional Brasil Argentina Vol. 10, num. 2, dez/2021, p. 390-405 
observados no seguinte trecho da SD2: "[...] teremos mais pessoas presas do que trabalhadores, e esse custo será insustentável causando uma deterioração da sociedade levando ao caos sem volta."

Dessa maneira, a FD neoliberal determina sentidos para o trabalho e para o sujeito exdetento, cuja reinclusão social passa a significar como uma reinserção à economia capitalista, pois o ex-criminoso deve tornar-se um trabalhador "produtivo" e "contribuinte de impostos" para a "manutenção da sociedade", ou seja, retorna ao status de "cidadão capitalista". Nesse discurso, o sentido de cidadania deve ser associado à capacidade produtiva e de consumo financeiro do indivíduo (MARCUSE, 1982), e assim o Direito ao esquecimento é desvirtuado de suas finalidades, pois se torna servo dos interesses capitalistas.

Prossigamos com a nossa terceira SD, constituída de três comentários:

Figura $3^{\text {vi }}-$ SD3

\section{PROFISSÃO REPÓRTER}

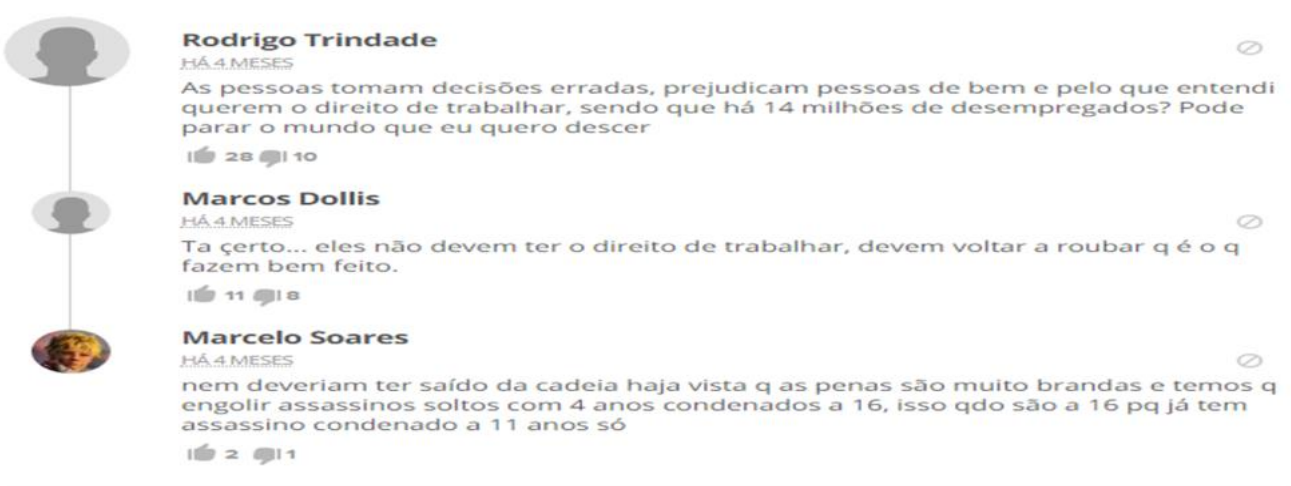

Ao observar a SD3, verificamos que a regularização dos sentidos punitivistas para o exdetento vai ganhando forças no espaço midiático digital. Na SD3, observamos que, no primeiro e no último comentário, os leitores (R.T. e M.S.), ao se inscreverem no discurso, ocupam a mesma posição-sujeito dominante nos comentários anteriores, que contraria o Direito ao esquecimento. Instaura-se, dessa forma, uma disputa de memórias, pois enquanto o discurso jurídico defende o esquecimento dos crimes do passado, para aquele que já cumpriram legalmente suas penas, o discurso midiático insiste em rememorar a marca de criminoso para o sujeito ex-detento.

Indursky (2015), em sua reflexão acerca da disputa entre a memória e o esquecimento dos crimes cometidos pelo Estado no período da ditadura militar brasileira (1964-1985), teoriza

Revista RBBA $\mid$ Revista Binacional Brasil Argentina Vol. 10, num. 2, dez/2021, p. 390-405 
sobre a política do esquecimento e a política do resgate da memória. Conforme a autora, enquanto o aparelho ideológico do Estado - AIE jurídico e o AIE da informação trabalham para o esquecimento das práticas criminosas da ditadura, a Comissão Nacional da da Verdade $(\mathrm{CNV})^{\mathrm{vii}}$ instaurou a Política de resgate da memória desses crimes, e assim travou-se um "jogo muito forte entre forças antagônicas e que pode ser interpretado como uma luta de poder entre a memória e o esquecimento" (INDURKY, 2015, p. 14).

Neste estudo, efetuamos um deslocamento das noções trabalhadas pela autora para pensar o Direito ao esquecimento como uma Política do esquecimento - AIE jurídico, e o punitivismo midiático - AIE da informação, como uma Política do resgate da memória dos crimes cometidos pelo sujeito ex-detento, mesmo após o cumprimento da pena.

A mídia trabalha incessantemente para resgatar/reavivar a memória de criminoso, impedindo, assim, a formação de uma nova identidade para o sujeito ex-detento, que fica estigmatizado e etiquetado socialmente. Mazoni e Fachin (2012), ao discorrerem sobre o etiquetamento jurídico, afirmam que o próprio sistema penal é responsável pela 'higienização' da sociedade e "Assim, etiquetam-se sujeitos tipificados através de interações sociais complexas como sendo delinquentes" (MAZONI e FACHIN, p. 5). A entrada ao cárcere coincide com a morte social do indivíduo, e a sua lícita saída do sistema prisional, o seu banimento estigmatizante. Dessa forma, uma vez etiquetados juridicamente e socialmente, a mídia continua o trabalho da "repetibilidade até a exaustão" (INDURSKY, 2015) para fixar ainda mais esse etiquetamento de 'bandido' no imaginário do sujeito ex-detento.

O etiquetamento jurídico, social e midiático pode também ser melhor entendido como uma técnica de gestão social dos indivíduos. Segundo Pêcheux (2008), ao domínio da técnica se associam as técnicas de gestão social dos indivíduos que buscam imprimir-lhes uma marca. Nas palavras do autor:

[...] A esta série vem se juntar a multiplicidade das 'técnicas' de gestão social dos indivíduos: marcá-los, identificá-los, classificá-los, compará-los, colocálos em ordem, em colunas, em tabelas, reuni-los e separá-los segundo critérios definidos, a fim de colocá-los no trabalho, a fim de instruí-los, de fazê-los sonhar ou delirar, de protegê-los e de vigiá-los, de levá-los à guerra e de lhes fazer filhos... Este espaço administrativo (jurídico, econômico e político) apresenta ele também as aparências da coerção lógica disjuntiva [...] (PÊCHEUX, 2008, p. 30, grifo nosso). 
Temos, pois, esse funcionamento de classificação e comparação das pessoas no primeiro comentário da SD3, ao comparar as pessoas desempregadas, presumidas como as "pessoas de bem”, com o ex-detento, uma não-pessoa. A ideologia punitivista determina efeitos de que reconhecer direitos sociais aos egressos significa suprimir os direitos do "cidadão de bem". Dessa maneira, as mídias digitais também podem funcionar como um espaço administrativo de gestão social das pessoas, como aparelho ideológico da informação (INDURSKY, 2015), que interpelam os indivíduos em sujeitos, visando fixar um sentido ao discurso. Os próprios internautas comentaristas das postagens digitais podem ser manipulados pela gestão social e midiática e, ao mesmo tempo, reproduzir essas marcas pela repetibilidade, instaurando a gestão dos sentidos e das pessoas.

Mas o sentido sempre pode ser outro. Na SD3 temos ainda o segundo comentário (M.D.), que materializa o discurso antagônico ao punitivismo, com efeitos de ironia: "eles não devem ter o direito de trabalhar, devem voltar a roubar q é o q fazem bem feito". Embora o internauta ocupe a posição-sujeito de defesa à ressocialização do ex-detento e sua reinclusão social pelo trabalho, funciona, nesse discurso, um atravessamento da memória de sentidos morais para o trabalho, discursivizado aqui como uma suposta "cura" para os males sociais. Novamente aqui, temos o funcionamento parafrástico do efeito de cidadania, afetado pelo discurso capitalista.

\section{5 (IN)CONCLUSÕES}

Com base nos dispositivos teóricos da Análise de Discurso e nos aportes do Direito ao esquecimento, foi possível compreender que o embate discursivo em funcionamento nos comentários digitais mobiliza memórias e imaginários acerca do sujeito (ex) condenado, e assim instaura o tensionamento entre as diversas posições-sujeito no discurso, quais sejam, a posição-sujeito punitivista, sendo esta a posição dominante; a posição-sujeito que defende a ressocialização e reinclusão do sujeito ex-detento, tendo em vista a restauração da sua dignidade e a construção de uma nova identidade para esse sujeito; e a posição-sujeito que defende a reintegração do ex-detento ao trabalho, apenas pelo interesse em sua força de trabalho, tendo em vista as determinações da ideologia neoliberal que rege o discurso capitalista.

Os comentários digitais se constituem em gestos de interpretação e na tomada de alguma posição-sujeito, pois os internautas, já afetados pela memória, pela história, são interpelados ideologicamente nas relações com a FD midiática. Nas materialidades analisadas, vimos que a

Revista RBBA $\mid$ Revista Binacional Brasil Argentina Vol. 10, num. 2, dez/2021, p. 390-405 
posição-sujeito punitivista é dominante no discurso dos comentários digitais, que sofre determinações da FD midiática sensacionalista. O discurso punitivista, afetado pelo imaginário de não-pessoa para o ex-condenado, produz efeitos de permanência da exclusão social do excondenado, discursivizado como um "mal” a ser socialmente excluído, já que, além de ser considerado "improdutivo", ainda quer ocupar (roubar) os empregos das "pessoas do bem".

Com base em Indursky (2015) podemos observar que funciona no discurso materializado nos comentários digitais, regido pelo AI da informação, um jogo de forças entre a memória punitivista - que busca reavivar e resgatar a memória da delinquência, instaurando a condenção ad infinitum (SANTANA e CRUZ, 2015) - e a política do esquecimento, do AI jurídico, pelo viés do Direito ao esquecimento, que defende a construção de uma nova memória e uma nova identidade para o ex-detento, tendo em vista o processo de sua ressocialização e reinclusão na sociedade.

Observamos, portanto, no discurso dos comentários digitais, uma disputa de sentidos e de memórias, acerca do sujeito ex-detento, um jogo de forças da memória (PÊCHEUX, 2010b), que movimenta uma tensa relação entre a estabilização e a perturbação dos sentidos já ditos.

\section{REFERÊNCIAS}

BRASIL Constituição da República Federativa do Brasil. Diário Oficial da União. 5 out. 1988.Disponívelem<http://www.planalto.gov.br/ccivil_03/constituicao/constituição.htm>.Ace sso em: 20 jan. 2020.

BRASIL. Superior Tribunal de Justiça. Recurso Especial. REsp No 1.334.097-RJ, $4^{\circ}$ Turma. Relator: Ministro Luis Felipe Salomão. DJe: 10 set. 2013. Disponível em: <https://ww2.stj.jus.br/processo/revista/documento/mediado/?componente=ATC\&sequen cial $=31006510 \&$ num_registro $=201201449107 \&$ data $=20130910 \&$ tipo $=5 \&$ formato $=P D F>$. Acesso em: 14 jan. 2020.

CORTES, Gerenice Ribeiro de Oliveira. Do lugar discursivo ao efeito-leitor: a movimentação do sujeito no discurso em blogs de divulgação científica. Tese (Doutorado)- Universidade Federal de Pernambuco. Centro de Artes e Comunicação. Letras, 2015.

COURTINE, Jean-Jacques. Análise do Discurso Político: o discurso comunista endereçado aos cristãos. São Carlos: Edufscar, 2009.

COURTINE, Jean-Jacques e MARANDIN, Jean-Marie. Que objeto para a análise de discurso? In: CONEIN, Bernard et al (Orgs). Materialidades discursivas. Campi nas, SP:Editora da UNICAMP, 2016, p. 33-54.

\begin{tabular}{l|l} 
Revista RBBA & Revista Binacional Brasil Argentina Vol. 10, num. 2, dez/2021, p. 390-405
\end{tabular} 
DOTTI, René Ariel. Proteção da vida privada e liberdade de informação. São Paulo: Revista dos Tribunais, 1980.

INDURSKY, Freda. Políticas do esquecimento x políticas de resgate da memória. In: FLORES, G. B.; GALLO, S. M. L.; LAGAZZI, S. Análise de discurso em rede: cultura e midia. V. 1. São Paulo: Pontes Editores, 2015. p. 11-27.

INDURSKY, Freda. A memória na cena do discurso. In.: INDURKY, F., MTTMAN, S. e FERREIRA, M.C.L. (Orgs.) Memória e história na/da análise do discurso. Campinas -SP: Mercado das Letras, 2011, p. 67-89.

INDURSKY, Freda. Unicidade, desdobramento, fragmentação: a trajetória da noção de sujeito em Análise do Discurso. In: MITTMANN, S.; GRIGOLETTO, E.; CAZARIN, E. (Orgs.). Práticas Discursivas e identitárias: Sujeito \& Língua. Porto Alegre, Nova Prova, PPGLetras/UFRGS, 2008, p. 9-33. (Col. Ensaios, 22).

LEMES, Thiago Morais de Almeida. A falaciosa ressocialização de presos no Brasil. Disponível em: https://ambitojuridico.com.br/cadernos/direito-penal/a-falaciosaressocializacao-de-presos-no-brasil/ . Acesso em 06/05/2021.

LEITE, Coralia Thalita Viana A. Memória, mídia e pensamento criminológico: enfoque em casos brasileiros (1988-2016). In: Anais do XII Colóquio Nacional e V Colóquio Internacional do Museu Pedagógico. Vitória da Conquista, Edições UESB, 2017.Disponível em: http://anais.uesb.br/index.php/cmp/article/view/6824. Acesso em 10 de maio de 2019.

MARCUSE, Herbert. Ideologia da sociedade industrial. Tradução: Giasone Rebuá. Rio de Janeiro: Zahar, 1982.

MALDIDIER, Denise. A inquietação do discurso: (re) ler Michel Pêcheux hoje. CampinasSP: Pontes, 2003, 110 p.

MARTINEZ, Pablo Dominguez. Direito ao esquecimento: A proteção da memória individual na sociedade da informação. Rio de Janeiro: Lumen Juris, 2014.

MAZONI, Ana Paula de O. e FACHIN, Melina Girardi. A teoria do etiquetamento do sistema penal e os crimes contra a ordem econômica: uma análise dos crimes de colarinho branco. In: Revista de Direito Público. Londrina-PR, v. 7, n. 1, p. 3-18, jan./abr. 2012.

MORALES, Blanca de Souza V. Sujeito: imaginário, simbólico e real. In: In: MITTMANN, S.; GRIGOLETTO, E.; CAZARIN, E. (Orgs.). Práticas Discursivas e identitárias: Sujeito \& Língua. Porto Alegre, Nova Prova, PPG-Letras/UFRGS, 2008, p. 34-46. (Col. Ensaios, 22).

ORLANDI, Eni P. Análise de Discurso: Princípios e Procedimentos. Pontes Editores, 10ª edição, 2012.

PÊCHEUX, Michel. Papel da memória. Trad. J. H. Nunes. In: ACHARD, Pierre et al. Papel da memória. Campinas-SP, Pontes Editores, (2010a), $3^{\text {a }}$ ed. p. 49-57.

Revista RBBA $\mid$ Revista Binacional Brasil Argentina Vol. 10, num. 2, dez/2021, p. 390-405 
Análise automática do discurso: (AAD-69). In.: GADET, F. e HAK, T. Por uma análise automática do discurso: uma introdução à obra de Michel Pêcheux. $4^{\mathrm{a}}$ ed. CampinasSP: Ed. da Unicamp, 2010b [1969], p. 59-158.

O discurso: estrutura ou acontecimento. $5^{\text {a }}$. ed. Campinas, SP: Pontes, (2008).

. Semântica e discurso: uma crítica à afirmação do óbvio. Campinas: UNICAMP, (2009 [1975]).

SANTANA, Everaldo F. e CRUZ, Aline Ribeiro. O direito ao esquecimento: os reflexos da mídia no processo de ressocialização. Revista Paradigma, Ribeirão Preto-SP, V. 24, N. 1, p. 295-314. jan./jun. 2015.

\section{NOTAS}

\footnotetext{
${ }^{\text {i }}$ Historicamente, a primeira manifestação do Direito ao Esquecimento é visualizada no caso Melvin versus Reid, em 1931, julgado pela Corte de Apelação da Califórnia, nos Estados Unidos (DOTTI, 1980).

ii No Brasil, em fevereiro de 2021, o Supremo Tribunal Federal, no julgamento do Recurso Extraordinário (RE), fixou a tese de que o Direito de ser esquecido é incompatível com a Constituição da República. Tal recurso reafirma a decisão do STJ no Recurso Especial número 1.335.153, no qual entendeu-se que os crimes genuinamente históricos são fatos notórios e de domínio público, portanto, insuscetíveis de aplicação do Direito de ser deixado em paz. Fonte: https://portal.stf.jus.br/notícias/verNotícias detalhe.asp?idConteudo+460414\&ori=1

iii Disponível em: < https://g1.globo.com/profissao-reporter/noticia/2019/09/26/ex-detentos-lutam-contra-opreconceito-por-oportunidade-no-mercado-trabalho.ghtml > Acesso em: 17/12/2019.

iv Disponível em: < https://g1.globo.com/profissao-reporter/noticia/2019/09/26/ex-detentos-lutam-contra-opreconceito-por-oportunidade-no-mercado-trabalho.ghtml > Acesso em: 17/12/2019. Todos os comentários estão disponíveis nesse link.

v Disponível em: < https://g1.globo.com/profissao-reporter/noticia/2019/09/26/ex-detentos-lutam-contra-opreconceito-por-oportunidade-no-mercado-trabalho.ghtml > Acesso em: 17/12/2019.

vi Disponível em: < https://g1.globo.com/profissao-reporter/noticia/2019/09/26/ex-detentos-lutam-contra-opreconceito-por-oportunidade-no-mercado-trabalho.ghtml > Acesso em: 17/12/2019.

vii A CNV foi instituída no governo Dilma Roussef, via Decreto, no ano de 2012.
}

Revista RBBA Revista Binacional Brasil Argentina Vol. 10, num. 2, dez/2021, p. 390-405 